\title{
DESEMPENHO DE SEMENTES DE MILHO EM RELAÇÃO À SUA LOCALIZAÇÃO NA ESPIGA
}

\author{
ANA LÚCIA PEREIRA KIKUTI ${ }^{1}$ \\ RAMON CORREIA DE VASCONCELOS ${ }^{2}$ \\ ANGELO MARINCEK ${ }^{3}$ \\ ABEILARD HENRIQUE FONSECA ${ }^{4}$
}

\begin{abstract}
RESUMO - As sementes arredondadas do ápice e da base da espiga de milho são separadas das achatadas quanto à espessura durante o beneficiamento, não sendo bem aceitas pelos agricultores. No entanto, no caso de produção de sementes básicas, essas sementes arredondadas têm sido comercializadas em razão de seu alto custo de produção. Com isso, objetivou-se neste trabalho estudar em duas cultivares de milho (AL 25 e BRS 106) o comportamento de sementes localizadas em pontos distintos da espiga (base, meio e ápice) quanto ao seu desempenho. $\mathrm{O}$ delineamento
\end{abstract}

experimental utilizado foi o inteiramente casualizado em esquema fatorial $2 \times 3 \times 2$ (2 genótipos; 3 localizações na espiga; submetidas ou não ao envelhecimento acelerado) com quatro repetições. A avaliação do desempenho das sementes foi realizada por meio dos testes de germinação, velocidade de germinação, emergência em solo + areia e teste de frio, e a sanidade, por meio do "Blotter test". Conclui-se que as sementes arredondadas localizadas no ápice da espiga apresentam desempenho inferior às sementes da base e do terço médio da espiga.

TERMOS PARA INDEXAÇÃO: Milho, localização, semente, vigor, cultivares.

\section{CORN SEED PERFORMANCE AND THEIR POSITION ON THE EAR}

\begin{abstract}
Rounded seeds at the end and at the base of corn ears are separated from the flat ones by thickness during the processing as the former not well being accepted by farmers. Nevertheless, in the case of production of basic seeds, those rounded seeds have been marketed due to their high production cost. So, in this work it was aimed to study, in two corn cultivars AL 25 and BRS 106, the behavior of seeds situated on distinct spots on the ear (base, middle, and tip) regarding their
\end{abstract}

INDEX TERMS: Corn, position, seed, vigor, cultivars.

\section{INTRODUÇÃO}

A qualidade das sementes de milho influencia a velocidade de estabelecimento da cultura e a uniformidade do estande, podendo, desse modo, afetar a produção de grãos. Com o intuito de uniformizar e facilitar a semeadura, as sementes de milho são classificadas durante o beneficiamento quanto ao tamanho (largura, espessura e comprimento), com a utilização de peneiras performance. The experimental design was completely randomized in a $2 \times 3 \times 2$ factorial scheme (two genotypes, three positions on the ear, submitted or not to accelerated aging) with four replications. Evaluation of performance was done by means of germination tests, germination velocity, emergence on soil + sand, cold test, and sanity by means of the "Blotter test". It is concluded that a round seeds situated at the tip of the ear performs inferiorly compared to seeds at base and at the middle of the ear.

\footnotetext{
1. Engenheiro Agrônomo, MS., Departamento de Agricultura, UNIVERSIDADE FEDERAL DE LAVRAS/UFLA - Caixa Postal 37, 37200-000, Lavras, MG.

2. Engenheiro Agrônomo, MS., Professor Assistente - Universidade Estadual do Sudoeste da Bahia (UESB). 3. Engenheiro Agrônomo, MS., Fitotecnia/UFLA.
4. Engenheiro Agrônomo, MS., Fitotecnia/UFLA. 3. Engenheiro Agrônomo, MS., Fitotecnia/UFLA.
4. Engenheiro Agrônomo, MS., Fitotecnia/UFLA.
}

de diferentes dimensões e de cilindro alveolado. Segundo Pinho et al. (1995), essa classificação das sementes permite a venda de um produto homogêneo, o que facilita a regulagem de semeadoras e proporciona distribuição mais uniforme das sementes no sulco de semeadura. As sementes arredondadas são comercializadas pelas empresas produtoras de sementes e freqüentemente são aproveitadas para a produção de sementes básicas, devido ao alto custo de produção dessas. 
Em uma espiga de milho, a fertilização dos óvulos não ocorre simultaneamente, resultando em desenvolvimento diferenciado e conseqüente formação de sementes de diferentes tamanhos. Esse fato faz com que as sementes da base, formando-se primeiramente, sejam maiores que aquelas desenvolvidas no ápice da espiga (Aldrich \& Leng, citados por Shieh \& McDonald, 1982). A espessura está relacionada com a pressão exercida por uma cariopse contra as outras circunvizinhas durante o enchimento dos grãos, levando à formação de sementes achatadas no terço médio da espiga, em razão da formação de sementes arredondadas na base e ápice, locais onde a pressão entre cariopses é menor (Wolf et al., citados por Shieh \& McDonald, 1982).

A infecção por microrganismos pode provocar o apodrecimento das sementes e a morte de plântulas em pré ou pós-emergência, diminuição do vigor inicial e aumento do grau de deterioração durante o armazenamento. $\mathrm{Na}$ base da espiga de milho ocorre maior acúmulo de água em relação a outras partes da espiga, provocando o aumento no teor de água das sementes, com conseqüente redução de seu desempenho. Desse modo, sementes situadas no terço médio da espiga e no ápice estariam mais protegidas e apresentariam melhor desempenho no campo que as sementes situadas na base.

Shieh \& McDonald (1982), em seus estudos, confirmaram que a influência do tamanho de sementes não foi significativa para emergência final no campo. Em contraste, a forma da semente afetou claramente o desempenho de híbridos, e as sementes curtas iniciaram o processo de embebição mais rapidamente, conferindo germinação mais rápida do que as sementes longas. Nessa mesma pesquisa, sementes arredondadas apresentaram maior número de plântulas na primeira contagem de germinação, bem como maior número de plântulas normais nos testes de frio e de envelhecimento acelerado em relação às sementes achatadas. No entanto, Moreno-Martinez et al. (1998) afirmaram que sementes de milho achatadas (maiores) do híbrido B-15 mantiveram maior viabilidade durante o armazenamento que as sementes arredondas (menores).

O desempenho das sementes pode ser influenciado por diversos fatores como ambiente, genótipo e a interação genótipo x ambiente. Orozco et al. (1995), avaliando o grau de deterioração das sementes de diferentes genótipos de milho (linhagens, variedades e híbridos) em duas condições de armazenamento, concluíram que as variedades foram mais sensíveis à deteriora- ção durante o armazenamento que os demais genótipos estudados.

O comportamento das sementes pode ser diferenciado durante o armazenamento, em função da qualidade inicial dessas. O envelhecimento acelerado é uma alternativa para avaliar o potencial relativo de armazenamento das sementes (Helmer et al., 1962, citados por Marcos Filho, 1994).

Realizou-se este trabalho com o objetivo de estudar em duas cultivares de milho (Zea mays L.) o comportamento de sementes localizadas em pontos distintos da espiga (base, meio e ápice) quanto à germinação, vigor e sanidade.

\section{MATERIAL E MÉTODOS}

As sementes de milho das cultivares AL 25 e BRS 106 foram provenientes dos campos de produção de sementes fiscalizadas da Empresa Santa Helena Sementes, no município de Paracatu - MG, no ano agrícola de 1999, safra das secas, conduzida com irrigação por aspersão. A colheita foi realizada em espigas amostradas aleatoriamente no campo, quando as espigas apresentaram um teor de água de $25 \%$ aproximadamente. Em seguida, as espigas foram transportadas até a unidade de beneficiamento de sementes da Universidade Federal de Lavras - UFLA, no município de Lavras - MG. Efetuaram-se, em seguida, a seleção das espigas que apresentaram bom empalhamento em ambas as cultivares, o despalhamento e secagem das espigas ao sol em terreiro de piso de cimento.

Após as sementes atingirem teor de água de $18 \%$, as espigas foram debulhadas manualmente, separando-se três partes (base, meio e ápice), que foram colocadas para secar ao sol até atingirem $13 \%$ de teor de água.

As sementes do ápice e da base das espigas foram classificadas separadamente em peneiras de crivos oblongos, sendo utilizadas para os testes subseqüentes apenas aquelas retidas na peneira 16x3/4. As sementes oriundas do meio da espiga foram classificadas quanto à largura, utilizando-se para os testes apenas aquelas retidas na peneira 22.

Após homogeneizadas, as sementes correspondentes a cada tratamento foram colocadas em um divisor de amostras, para a formação de quatro repetições. Em seguida, retiraram-se de cada repetição 40 gramas de sementes para a realização do Blotter test. Todas as sementes restantes foram submetidas a tratamento químico, conforme discriminado na Tabela 1. 
TABELA 1 - Produtos e dosagens utilizadas no tratamento químico de sementes de milho. UFLA, Lavras, MG, 2001.

\begin{tabular}{cccc}
\hline Produto Comercial & Doses $(\mathbf{m L} / \mathbf{t})$ & Princípio Ativo & Função \\
\hline Água & 15000 & - & Diluente/ veículo \\
K-Obiol & 33,3 & Deltametrina 2,5\% & Inseticida \\
Actellic & 33,3 & Pirimifós metil 50\% & Inseticida \\
Haiten & 75 & - & Espalh. Adesivo \\
Captan 75 & 1000 & Captan 75\% & Fungicida \\
Tecto 600 & 400 & Thiabendazole & Fungicida \\
Corante & 500 & Rodamina & Corante \\
\hline
\end{tabular}

Uma parte das sementes tratadas foi submetida ao envelhecimento acelerado a $42^{\circ} \mathrm{C}$ por 96 horas, com o objetivo de obter lotes com diferentes potenciais fisiológicos; a outra parte das sementes não foi envelhecida.

Para cada tratamento, foram realizados os seguintes testes: germinação (Brasil, 1992); velocidade de germinação (Edmond \& Drapalla, 1958); frio (ISTA, 1995); emergência em solo + areia (estande aos 21 dias após semeadura), e sanidade por meio do "Blotter test" (Machado, 1988).

Foi utilizado o delineamento experimental inteiramente casualizado, em esquema fatorial $2 \times 3 \times 2$ ( 2 genótipos; 3 localizações na espiga; sementes envelhecidas e não envelhecidas), com 4 repetições. As análises de variância foram realizadas utilizando o programa SANEST, com teste de Duncan para a comparação das médias.

\section{RESULTADOS E DISCUSSÃO}

De acordo com a análise estatística, na avaliação do teste de germinação, houve efeito significativo apenas para o genótipo. A velocidade de germinação foi significativamente influenciada pelo genótipo, nível de qualidade, posição das sementes na espiga e interações posição versus genótipo e posição da semente na espiga versus nível de qualidade.

De uma maneira geral, as sementes localizadas no terço médio da espiga apresentaram maior velocidade de germinação (menores valores), quando comparadas às sementes localizadas na base e no ápice da espiga, e para essas últimas, foram observados os maiores valores, independentemente do ní- vel de qualidade das sementes (Tabela 2) ou da cultivar em questão (Tabela 3).

TABELA 2 - Velocidade de germinação (dias) de sementes milho localizadas em diferentes posições da espiga, com diferentes qualidades fisiológicas. UFLA, Lavras - MG, 1999.

\begin{tabular}{lccc}
\hline \multirow{2}{*}{ Envelhecimento } & \multicolumn{3}{c}{ Posição da semente na espiga } \\
\cline { 2 - 4 } & Base & Meio & Ápice \\
\hline Não Envelhecida & 2,04 b A & 1,98 a B & 2,15 c B \\
Envelhecida & 2,03 b A & 1,87 a A & 2,10 c A \\
\hline
\end{tabular}

Coeficiente de variação $=2,04 \%$.

Médias seguidas de mesma letra minúscula na linha e letra maiúscula na coluna não diferem significativamente entre si pelo teste de Duncan a $5 \%$ de probabilidade.

As sementes localizadas no ápice e no terço médio da espiga submetidas ao envelhecimento acelerado (envelhecidas) germinaram mais rapidamente do que as sementes não envelhecidas (Tabela 2). Esse comportamento também foi observado em sementes de milho por Brandão Júnior (1996).

As sementes do ápice da espiga estão mais sujeitas às intempéries, tais como temperatura, exposição a patógenos e umedecimento, que contribuem para maior deterioração. A água acumula-se nas sementes da base da espiga em razão da posição de inserção da espiga na planta, reduzindo a qualidade dessas sementes. De a- 
cordo com os resultados observados na análise sanitária, foi possível detectar maior infestação por fungos de armazenamento e de campo nas sementes do ápice e da base das espigas, provavelmente contribuindo para a redução da qualidade das sementes (Tabela 4).

TABELA 3 - Velocidade de germinação (dias) de sementes milho localizadas em diferentes posições da espiga nas cultivares AL 25 e BRS 106. UFLA, Lavras MG, 1999.

\begin{tabular}{cccc}
\hline \multirow{2}{*}{ Genótipos } & \multicolumn{3}{c}{ Posição da semente na espiga } \\
\cline { 2 - 4 } & Base & Meio & Ápice \\
\hline 'AL 25' & $2,01 \mathrm{~b}$ & 1,86 a & 2,08 c \\
'BRS 106' & $\mathbf{2 , 0 6} \mathbf{b}$ & $\mathbf{1 , 9 9}$ a & $\mathbf{2 , 1 7} \mathbf{c}$ \\
\hline
\end{tabular}

Coeficiente de variação $=2,04 \%$.

Médias seguidas de mesma letra minúscula na linha não diferem significativamente entre si pelo teste de Duncan a 5\% de probabilidade.

No teste de emergência em solo e areia (estande 21 após semeadura), houve efeito significativo para os parâmetros posição das sementes na espiga e nível de qualidade.

As sementes envelhecidas das cultivares AL 25 e BRS 106 apresentaram maior porcentagem de plântulas emersas $(95,50 \%)$ do que aquelas não envelhecidas $(92,83 \%)$. Nesse mesmo teste, sementes localizadas no ápice da espiga apresentaram 90,13\% de plântulas emersas, sendo esse valor significativamente inferior à porcentagem de plântulas emersas provenientes da base $(96,50 \%)$ e do terço médio da espiga $(95,88 \%)$, que foram estatisticamente semelhantes. Essa mesma tendência já havia sido observada no teste velocidade de germinação.

Para o teste de frio, foram observados efeitos significativos para os parâmetros posição das sementes na espiga e nível de qualidade e para a interação posição versus nível de qualidade (Tabela 5). As sementes do ápice da espiga apresentaram menores porcentagens de plântulas normais em relação às observadas para as sementes das demais posições, independentemente de a semente ter sido envelhecida ou não (Tabela 5). Para a cultivar 'AL25', as sementes localizadas no ápice da espiga não envelhecidas apresentaram elevada infestação de Fusarium graminearum (Tabela 6), o que, aliado aos patógenos presentes no solo e às condições favoráveis ao seu desenvolvimento no teste de frio, contribuiu para redução no número de plântulas normais em relação às sementes envelhecidas, em que provavelmente as condições de elevada temperatura e umidade foram desfavoráveis, reduzindo a incidência desse fungo. Fusarium graminearum pode ser eliminado das sementes de milho entre três e seis meses de armazenamento (Kabeere et al., 1997).

TABELA 4 - Infestação por fungos (\%) obtida no teste de sanidade em sementes de milho localizadas em diferentes posições na espiga, sem tratamento fungicida e não envelhecidas, para as cultivares AL 25 e BRS 106. UFLA, Lavras - MG. 1999.

\begin{tabular}{|c|c|c|c|c|c|c|}
\hline \multirow{4}{*}{ Fungos } & \multicolumn{6}{|c|}{ Cultivares } \\
\hline & \multicolumn{3}{|c|}{ BRS 106} & \multicolumn{3}{|c|}{ AL 25} \\
\hline & \multicolumn{6}{|c|}{ Posição da semente na espiga } \\
\hline & Base & Meio & Ápice & Base & Meio & Ápice \\
\hline Fusarium graminearum & 46 & 21 & 26 & 52 & 27 & 55 \\
\hline Penicillium sp. & 96 & 100 & 100 & 100 & 100 & 100 \\
\hline Cephalosporium. acremonium & 01 & 00 & 00 & 00 & 00 & 01 \\
\hline Cladosporium sp. & 01 & 00 & 00 & 03 & 00 & 00 \\
\hline Aspergillus niger & 00 & 00 & 00 & 01 & 01 & 00 \\
\hline Aspergillus flavus & 00 & 00 & 00 & 00 & 01 & 00 \\
\hline
\end{tabular}

Ciênc. agrotec., Lavras. V.27, n.4, p.765-770, jul./ago., 2003 
Pelos resultados obtidos na análise sanitária das sementes não tratadas, constatou-se maior incidência dos fungos Fusarium graminearum e Penicillium sp. em ambas as cultivares (Tabela 4). A infestação por Penicillium sp. foi de $100 \%$, independente da posição das sementes na espiga e das cultivares. Foi verificada ainda maior incidência de Fusarium graminearum na base $(46 \%)$, em relação ao ápice $(26 \%)$ e ao meio $(21 \%)$, para a cultivar BRS 106.

Para a cultivar AL 25, a infestação de Fusarium graminearum concentrou-se mais no ápice $(55 \%)$ e na base $(52 \%)$, em relação ao meio (27\%). Essa tendência pode ter ocorrido em conseqüência da maior concentração de água na base da espiga e da maior exposição das sementes do ápice, o que contribuiu para o desenvolvimento do fungo.

Os demais fungos (Cephalosporium acremonium, Cladosporium sp., Aspergillus niger e Aspergillus flavus) não apresentaram níveis de infestação diferenciados para as sementes localizadas nas diferentes posições na espiga e para as cultivares, situando-se, em média, abaixo de 1\% (Tabela 4).

Nas sementes tratadas, submetidas ao envelhecimento acelerado, foi observado para a cultivar AL 25 elevado índice de infestação de Penicillium sp. e Fusarium graminearum no ápice da espiga. No entanto, para a cultivar BRS 106, a maior infestação de Fusarium graminearum foi encontrada nas sementes situadas no terço médio da espiga (Tabela 6).

TABELA 5 - Porcentagem de plântulas normais obtidas no teste de frio em sementes de milho localizadas em diferentes posições da espiga, com diferentes qualidades fisiológicas. UFLA, Lavras-MG, 1999.

\begin{tabular}{cccc}
\hline \multirow{2}{*}{ Envelhecimento } & \multicolumn{3}{c}{ Posição da semente na espiga } \\
\cline { 2 - 4 } & Base & Meio & Ápice \\
\hline Não Envelhecida & $96,50 \mathrm{a}$ & $96,50 \mathrm{a}$ & $85,25 \mathrm{~b}$ \\
Envelhecida & $97,25 \mathrm{a}$ & $96,00 \mathrm{a}$ & $92,00 \mathrm{~b}$ \\
\hline
\end{tabular}

Coeficiente de variação $=3,56 \%$.

Médias seguidas de mesma letra minúscula na linha não diferem significativamente entre si pelo teste de Duncan a $5 \%$ de probabilidade.

TABELA 6 - Porcentagem de infestação por fungos obtida no teste de sanidade em sementes de milho localizadas em diferentes posições na espiga, com diferentes qualidades fisiológicas, tratadas com fungicida, para as cultivares AL 25 e BRS 106. UFLA, Lavras - MG. 1999.

\begin{tabular}{|c|c|c|c|c|c|c|c|c|c|c|c|c|}
\hline \multirow{6}{*}{ Fungos } & \multicolumn{12}{|c|}{ Envelhecimento } \\
\hline & \multicolumn{6}{|c|}{ Sementes não envelhecidas } & \multicolumn{6}{|c|}{ Sementes envelhecidas } \\
\hline & \multicolumn{12}{|c|}{ Genótipos } \\
\hline & \multicolumn{3}{|c|}{ AL 25} & \multicolumn{3}{|c|}{ BRS 106} & \multicolumn{3}{|c|}{ AL 25} & \multicolumn{3}{|c|}{ BRS 106} \\
\hline & \multicolumn{12}{|c|}{ Posição da semente na espiga } \\
\hline & B & $\mathbf{M}$ & $\mathbf{A}$ & B & $\mathbf{M}$ & $\mathbf{A}$ & B & $\mathbf{M}$ & $\mathbf{A}$ & B & $\mathbf{M}$ & $\mathbf{A}$ \\
\hline F. graminearum & 00 & 02 & 64 & 00 & 22 & 00 & 02 & 00 & 06 & 04 & 04 & 00 \\
\hline Penicillium sp. & 00 & 00 & 74 & 00 & 00 & 00 & 00 & 00 & 90 & 00 & 00 & 00 \\
\hline Drechslera turcica & 00 & 00 & 06 & 00 & 00 & 00 & 00 & 00 & 00 & 00 & 00 & 00 \\
\hline Aspergillus niger & 00 & 00 & 00 & 00 & 00 & 00 & 00 & 00 & 00 & 02 & 00 & 00 \\
\hline Aspergilus flavus & 00 & 00 & 00 & 00 & 00 & 00 & 02 & 00 & 48 & 00 & 00 & 00 \\
\hline
\end{tabular}

B - Base M - Meio A - Ápice 
Para ambas as cultivares, houve tendência de redução da infestação de Fusarium graminearum quando as sementes foram submetidas ao envelhecimento (Tabela 6), concordando com (Kabeere et al., 1997). A incidência de $74 \%$ de Penicillium sp. foi observada em sementes não envelhecidas, e de $90 \%$, em sementes envelhecidas na cultivar AL 25 situadas no ápice da espiga. Isso pode ter ocorrido em razão das condições em que o teste foi realizado (alta temperatura e UR), propiciando o desenvolvimento desses patógenos. (McLean \& Berjak, 1987).

A incidência de Aspergillus flavus também só foi observada após o envelhecimento, nas sementes do ápice da espiga da cultivar AL 25. O tratamento das sementes parece não ter sido eficaz nas condições em que o envelhecimento acelerado foi conduzido, favorecendo o desenvolvimento dos fungos que se encontravam internamente à semente. Segundo Sauer et al. (1984), esses fungos invadem as sementes durante seu desenvolvimento ou após a maturidade fisiológica, ainda no campo.

\section{CONCLUSÕES}

As sementes arredondadas localizadas no ápice da espiga apresentam desempenho inferior às sementes da base e do terço médio da espiga.

\section{REFERÊNCIAS BIBLIOGRÁFICAS}

BRANDÃO JUNIOR, D. S. Eletroforese de proteína e isoenzima na avaliação da qualidade de sementes de milho. 1996. 110 f. Dissertação (Mestrado em Agronomia) - Universidade Federal de Lavras, Lavras.

BRASIL. Ministério da Agricultura e Reforma Agrária. Secretaria Nacional de Defesa Agropecuária. Departamento Nacional de Defesa Vegetal. Coordenação de Laboratório Vegetal. Regras para análise de sementes. Brasília, 1992. 365 p.

EDMOND, J. B.; DRAPALLA, W. J. The effects of temperature, sand and soil, and acetone on germination of okra seeds. Proceedings of the American Society for Horticultural Science, Alexandria, v. 71, p. 428434, 1958.

KABEERE, F.; HILL, M. J.; HAMPTON, J. G. Effect of maize seed storage conditions on the survival of
Fusarium spp. Seed Science and Technology, Zurich, v. 25, n. 2, p. 329-332, 1997.

INTERNATIONAL SEED TESTING ASSOCIATION. International rules for testing seed. Seed Science and Tecnology, Zurich, v. 13, n. 2, p. 300-520, 1995.

MACHADO, J. C. Patologia de sementes: fundamentos e aplicações. Brasília: MEC/ ESAL/FAEPE, 1988. 107 p.

McLEAN, M.; BERJAK, P. Maize grains and their associated mycoflora a microecological consideration. Seed Science and Tecnology, Zurique, v. 15, n. 3, p. 831-850, 1987.

MARCOS FILHO, J. Teste de envelhecimento acelerado. In: VIEIRA, R. D.; CARVALHO, N. M. Testes de vigor em sementes. Jaboticabal: FUNEP, 1994. p. 133149.

MORENO-MARTINEZ，E.; VAZQUEZ-BADILLO, M. E.; RIVERA, A.; NAVARRETE, R.; ESQUIVELVILLAGRANA, F. Effect of seed shape and size on germination of corn (Zea mays L.) stored under adverse conditions. Seed Science and Technology, Zurique, v. 26, n. 2, p. 439-448, 1998.

OROZCO, J.; BAENA, D.; GOMEZ, C. Performance of five groups of maize (Zea mays L.) genotypes with two grains types in two conditions of storage. Acta Agronomica, Palmira, v. 45, p. 15-21, 1995.

PINHO, E. V. R. von; SILVEIRA, J. F.; VIEIRA, M. G. G. C. Influência do tamanho e do tratamento de sementes de milho na preservação da qualidade durante o armazenamento e posterior comportamento no campo. Ciência e Prática, Lavras, v. 19, n. 1, p. 30-36, 1995.

SAUER, D. B.; STOREY, C. L.; WALKER, D. E. Fungal populations in U.S. Farm. Stored grain and their relationship to moinsture, storage time, region and insect infestation. Phytopathology, Saint Paul, v. 74, p. 1050-1053, 1984.

SHIEH, W. J.; McDONALD, M. B. The influence of seed size, shape and treatment on inbred seed corn quality. Seed Science and Technology, Zurich, v. 10, n. 2, p. 307-313, 1982. 